\title{
Multiple bladder diverticula with Williams-Beuren syndrome: a case report
}

\author{
Jing Chen ${ }^{1}$, Jianhua Mao ${ }^{2}$, Lezhen Ye ${ }^{1}$, Dongmei Zong ${ }^{1}$, Xiaohui Qiao ${ }^{1}$ \\ ${ }^{1}$ Department of Nephrology, Ningbo Women and Children's Hospital, Ningbo, China; ${ }^{2}$ Department of Nephrology, Children's Hospital, Zhejiang \\ University School of Medicine, Hangzhou, China \\ Correspondence to: Xiaohui Qiao, MD. Department of Nephrology, Ningbo Women and Children's Hospital, 339 Liuting Street, Ningbo 315012 , \\ China. Email: qiaoxhui9@sina.com.
}

\begin{abstract}
Williams-Beuren syndrome (WBS) is an autosomal dominant disorder caused by a gene deletion on chromosome 7q11.23. Patients with WBS usually show a group of features such as developmental delay, cardiovascular anomalies, mental retardation, and characteristic facial appearance. It occurs in 1:7,500 live births and affects males and females equally. Recent studies showed that lower urinary tract symptoms were also frequent in WBS patients. However, there is extremely rare study report non-monosymptomatic nocturnal enuresis as the main manifestation of Williams syndrome in children. We reported a child with non-monosymptomatic nocturnal enuresis and multiple bladder diverticula as the main implications of Williams syndrome. A 7.6-year-old girl was admitted to our hospital due to frequent micturition, urgency, and nocturnal enuresis for 4 years, and B ultrasound of urinary system revealed multiple bladder diverticula. The patient was found to have 7q11.23 deletion that involves the elastin gene for WBS. Multiple bladder diverticula in WBS patients can lead to many lower urinary tract symptoms. The treatment for the lower urinary tract symptoms in WBS patients with multiple bladder diverticula is lacking. Lower urinary tract symptoms should be considered as a significant indicator of the clinical diagnosis of WBS and have a significant negative impact on patient's quality of life.
\end{abstract}

Keywords: Non-monosymptomatic nocturnal enuresis; Williams-Beuren syndrome; bladder diverticula

Submitted Sep 04, 2020. Accepted for publication Dec 08, 2020.

doi: $10.21037 /$ tp-20-311

View this article at: http://dx.doi.org/10.21037/tp-20-311

\section{Introduction}

Williams-Beuren syndrome (WBS) is an autosomal dominant disorder because of $7 \mathrm{q} 11.23$ microdeletion. It occurs in 1:7,500 live births and affects males and females equally (1). Clinically, the final diagnosis of WS requires genetic testing to prove gene deletion in WBSCR (2). The children with WBS are characterized by congenital heart disease, distinctive facies (Elfin-like features), hypercalcemia, connective tissue, abnormalities, growth retardation, intellectual disability, behavior deficits, and a gregarious personality $(3,4)$. It may lead to complications of kidney stones, hypothyroidism, hyperopia and recurrent otitis media. WBS requires multidisciplinary treatment, such as heart care, diet adjustment, calcium level testing and hormone therapy. Children with neurodevelopmental disorders even need screening for vision and hearing (5). Recent studies showed that lower urinary tract symptoms were also frequent in WBS patients $(6,7)$. These studies also showed that lower urinary tract symptoms have a significant negative impact on patients' quality of life. Multiple bladder diverticula in WBS patients can lead to many lower urinary tract symptoms. The treatment for the lower urinary tract symptoms in WBS patients with multiple bladder diverticula is lacking. Here, we reported a WBS child with multiple bladder diverticula who was treated with desmopressin for nocturnal enuresis. This case showed that desmopressin was still effective in treating nocturnal enuresis in WBS patients for a 4-month treatment.

We present the following article in accordance with 

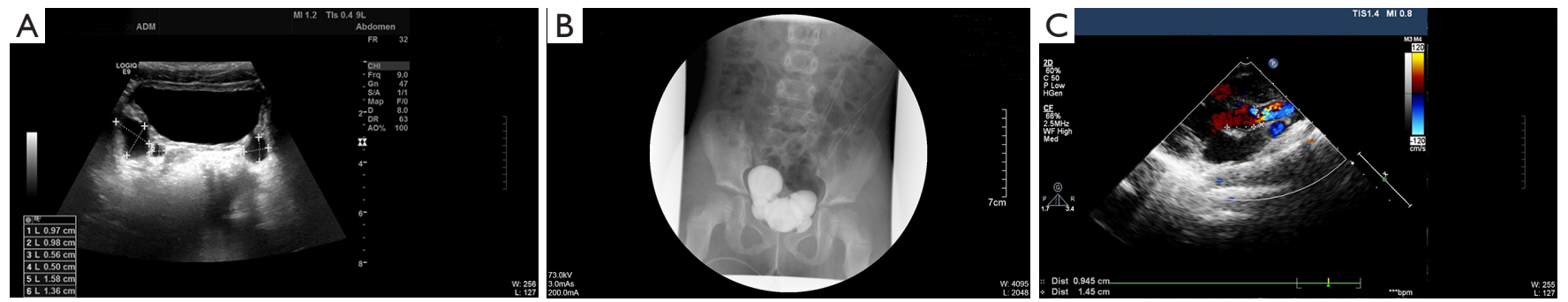

Figure 1 Ultrasound and retrograde urography results of the patient. (A) Ultrasound results showed multiple bladder diverticula; (B) retrograde urography results showed multiple bladder diverticula without cystoureteral reflux; (C) echocardiography showing supraaortic stenosis.

the CARE reporting checklist (available at http://dx.doi. org/10.21037/tp-20-311).

\section{Case presentation}

All procedures performed in studies involving human participants were in accordance with the ethical standards of the institutional and/or national research committee(s) and with the Helsinki Declaration (as revised in 2013). Written informed consent was obtained from the patient.

A 7.6-year-old girl was initially hospitalized with the complaint of urinary frequency, urgency, and nocturnal enuresis (the frequency of bed-wetting was 4-6 nights/ week) for four years. The child denied urinary pain or interruption. The child had growth retardation and malnutrition (weight $16.4 \mathrm{~kg}$ and height $113 \mathrm{~cm}$ ). Physical examination showed a grade III ejection systolic murmur at the second intercostal space on the right on the right of the sternum. Laboratory tests revealed that urine testing was regular, without proteinuria and hematuria. Urine electrolyte excretion in 24 hours, blood electrolyte, and renin-angiotensin-aldosterone activity (upright and horizontal) are normal. Blood glucose and glycosylated hemoglobin are typical. Lumbosacral MRI with T1 and T2 images is normal.

Further, the retrograde urography results showed multiple diverticula of the bladder (Figure 1A,B). Urodynamics results showed an overactive and sensitive bladder, with a decreased bladder volume. Echocardiography results showed supra-aortic stenosis (Figure 1C). The patient had moderate mental retardation with an IQ of 50 by the Wechsler intelligence test. Analysis of multiple ligase probe dependent amplification revealed heterozygous deletion in the elastin gene in the $7 \mathrm{q} 11.23$ region of the seventh chromosome, which was consistent with WS. The parents of the child refused to undertake repair surgery of the diverticulum and cardiac surgery. The patient received desmopressin $(0.2 \mathrm{mg}$, qn) and bladder function training. The nocturnal enuresis improved obviously during hospitalization. After four months follow-up, the nocturnal enuresis improved obviously (the frequency of bed-wetting was 1-2 nights/week). In comparison, the symptoms of urinary frequency and urgency did not improve.

\section{Discussion}

WBS is characterized as distinctive facial features, cardiovascular problems (including supravalvular aortic stenosis), hypercalcemia, endocrine problems, attentiondeficit/hyperactivity disorder, anxiety, and mild to moderate intellectual disability. Urological abnormalities (including renal ectopia, agenesis, hypoplasia, duplication, horseshoe kidney, hydronephrosis, and vesicoureteral reflux) in patients with WBS were also reported $(8,9)$. Recent studies showed that lower urinary tract symptoms were common in people with WBS $(6,7)$. The most prevalent symptoms are increased urinary frequency, urgency, urge incontinence, and enuresis, which may affect up to $78 \%$ of those with WBS (7). Lower urinary tract symptoms seriously affect the quality of life of patients. Sammour et al. showed that oxybutynin could improve lower urinary tract symptoms and the quality of life of patients (10).

To our knowledge, only three articles reported 13 cases of WBS with bladder diverticulum (11-13). In these patients, only one article had reported the detailed baseline characteristics of four patients (11). In these 13 patients, two male adult patients were included (35.4 and 39 years), and a urinary tract infection was reported in three patients. Most patients had symptoms of frequency and nocturnal enuresis. In the four patients, three patients were treated with Oxybutyni and one patient with Hyoscyamine. However, symptoms were no improved in a patient treated 
with Oxybutyni. In our patient, the child had urinary frequency, urgency, and nocturnal enuresis and was treated with desmopressin.

Desmopressin is an effective drug for the treatment of lower urinary tract symptoms. A recent meta-analysis showed that desmopressin, combined with an alarm, could effectively treat nocturnal enuresis (14). Desmopressin can also effectively treat nocturnal polyuria. A systematic meta-analysis showed that desmopressin was more effective than a placebo in terms of reduced nocturnal voiding frequency and duration of undisturbed sleep (15). The mechanism of nocturnal enuresis in patients with WBS is still unclear.

However, our case showed that desmopressin was still effective in treating nocturnal enuresis in WBS patients for a 4-month treatment. Although the symptoms of urinary frequency and urgency did not relieve, we surmised it was due to the bladder diverticulum, which had not been treated. Hyponatremia is a severe side effect of desmopressin therapy; serum sodium levels should be closely monitored during treatment (15). Even though this side effect was not observed in this child, it should be closely monitored in subsequent treatment.

\section{Acknowledgments}

Funding: None.

\section{Footnote}

Reporting Checklist: The authors have completed the CARE reporting checklist. Available at http://dx.doi.org/10.21037/ tp-20-311

Conflicts of Interest: All authors have completed the ICMJE uniform disclosure form (available at http://dx.doi. org/10.21037/tp-20-311). The authors have no conflicts of interest to declare.

Ethical Statement: The authors are accountable for all aspects of the work in ensuring that questions related to the accuracy or integrity of any part of the work are appropriately investigated and resolved. All procedures performed in studies involving human participants were in accordance with the ethical standards of the institutional and national research committee and with the Helsinki Declaration (as revised in 2013). Written informed consent was obtained from the patient.
Open Access Statement: This is an Open Access article distributed in accordance with the Creative Commons Attribution-NonCommercial-NoDerivs 4.0 International License (CC BY-NC-ND 4.0), which permits the noncommercial replication and distribution of the article with the strict proviso that no changes or edits are made and the original work is properly cited (including links to both the formal publication through the relevant DOI and the license). See: https://creativecommons.org/licenses/by-nc-nd/4.0/.

\section{References}

1. Pitts CH, Mervis CB. Performance on the Kaufman Brief Intelligence Test-2 by Children With Williams Syndrome. Am J Intellect Dev Disabil 2016;121:33-47.

2. Morris CA. Williams Syndrome. In: Adam MP, Ardinger HH, Pagon RA, et al. editors. GeneReviews(®). Seattle (WA): University of Washington, Seattle Copyright (C) 1993-2020, University of Washington, Seattle. GeneReviews is a registered trademark of the University of Washington, Seattle. All rights reserved; 1993.

3. Protopapas AD. Elastin deficiency in Williams syndrome may explain postoperative major adverse cardiac events. J Thorac Cardiovasc Surg 2015;150:1380.

4. Pober BR. Williams-Beuren syndrome. N Engl J Med 2010;362:239-52.

5. Wilson M, Carter IB. Williams Syndrome. StatPearls. Treasure Island (FL): StatPearls Publishing Copyright (C) 2020, StatPearls Publishing LLC.; 2020.

6. Sammour ZM, de Bessa J Jr, Hisano M, et al. Lower urinary tract symptoms in children and adolescents with Williams-Beuren syndrome. J Pediatr Urol 2017;13:203. e1-203.e6.

7. Sammour ZM, Gomes CM, Duarte RJ, et al. Voiding dysfunction and the Williams-Beuren syndrome: a clinical and urodynamic investigation. J Urol 2006;175:1472-6.

8. Pankau R, Partsch CJ, Winter M, et al. Incidence and spectrum of renal abnormalities in Williams-Beuren syndrome. Am J Med Genet 1996;63:301-4.

9. Suzuki Y, Shimazaki S, Kaneko K, et al. Renal abnormalities associated with Williams syndrome. J Pediatr 1992;121:667.

10. Sammour ZM, Gomes CM, de Bessa J Jr, et al. The effects of oxybutynin on urinary symptoms in children with Williams-Beuren syndrome. J Urol 2012;188:253-7.

11. Schulman SL, Zderic S, Kaplan P. Increased prevalence of urinary symptoms and voiding dysfunction in Williams syndrome. J Pediatr 1996;129:466-9. 
12. Babbitt DP, Dobbs J, Boedecker RA. Multiple bladder diverticula in Williams "Elfin-Facies" syndrome. Pediatr Radiol 1979;8:29-31.

13. Stagi S, Lapi E, Martini E, et al. Giant multiple bladder diverticula in Williams-Beuren syndrome. Kidney Int 2015;88:416.

14. Song P, Huang C, Wang Y, et al. Comparison of desmopressin, alarm, desmopressin plus alarm, and desmopressin plus anticholinergic agents in the management

Cite this article as: Chen J, Mao J, Ye L, Zong D, Qiao X. Multiple bladder diverticula with Williams-Beuren syndrome: a case report. Transl Pediatr 2020;9(6):863-866. doi: 10.21037/ tp-20-311 of paediatric monosymptomatic nocturnal enuresis: a network meta-analysis. BJU Int 2019;123:388-400.

15. Sakalis VI, Karavitakis M, Bedretdinova D, et al. Medical Treatment of Nocturia in Men with Lower Urinary Tract Symptoms: Systematic Review by the European Association of Urology Guidelines Panel for Male Lower Urinary Tract Symptoms. Eur Urol 2017;72:757-69.

(English Language Editor: J. Chapnick) 